\title{
New species and new records of Tonnoira (Diptera: Psychodidae) from Brazil
}

\author{
Freddy Bravo ${ }^{1,2}$; Naiara Vilarinho ${ }^{1,3}$ \& Maíra Xavier Araújo $0^{1,4}$ \\ 1 Universidade Estadual de Feira de Santana (UEFS), Departamento de Ciências Biológicas (DCBIO), Laboratório de Sistemática de Insetos \\ (LASIS). Feira de Santana, BA, Brasil. \\ ${ }^{2}$ ORCID: http://orcid.org/0000-0003-0959-0767.E-mail: fbravo@uefs.br \\ 3 ORCID: http://orcid.org/0000-0002-9593-2147. E-mail: nvilari93@gmail.com \\ ${ }^{4}$ ORCID: http://orcid.org/0000-0003-2447-9901. E-mail: mah.biology@gmail.com
}

\begin{abstract}
A new species of moth-fly, Tonnoira igrapiunensis sp. nov. (Psychodidae, Psychodinae), from the Brazilian Atlantic Rain Forest is described. The new species can be distinguished from other species of the genus by its eye bridge separated by 0.5 facet diameter, $\mathrm{R}_{5}$ ending slightly posterior to apex of the wing, gonostyli bifurcated with long arm shorter than length of gonocoxites, aedeagus bipartite and asymmetrical, and two asymmetrical parameres. The gonostylus is similar to that of Tonnoira andradei Santos, 2014, but in the latter species the aedeagus has only one shaft and not two as in the new species. Tonnoira bifida Bravo \& Chagas, 2004, Tonnoira brisolaii Santos, 2014, and Tonnoira galatiae Santos, 2014 have their distribution expanded.
\end{abstract}

Key-Words. Psychodinae; Maruinini; Moth fly; Atlantic Rain Forest; Neotropical Region.

\section{INTRODUCTION}

The American genus Tonnoira Enderlein, 1937 (Psychodinae) has been recorded from Nicaragua to Brazil (Espírito Santo State), with no records for the Caribbean islands. Twenty-five species are currently known for the genus (Bravo et al., 2008; Chagas-Vieira, 2012; Santos \& Curler, 2014). There are records of seventeen Tonnoira species in Brazil, which represents $70 \%$ of all known species in that genus (Bravo \& Chagas, 2004; Bravo et al., 2008; Quate \& Brown, 2004; Chagas-Vieira, 2012; Santos $\&$ Curler, 2014). We describe here a new species of Tonnoira from the Atlantic Rain Forest of Bahia State, Brazil, and expand the distributions of three previously described species.

\section{MATERIAL AND METHODS}

The specimens described here were collected by Dr. Sergio Andena and collaborators using Malaise and Pennsylvania light traps during an insect inventory in the Reserva Ecológica da Michelin (Michelin Ecological Reserve, $13^{\circ} 46^{\prime} 53^{\prime \prime}$; $38^{\circ} 49^{\prime} 44^{\prime \prime}$ W), which is located in the Central Corridor of the Atlantic Rain Forest, Bahia State. The Psychodidae specimens were collected in one of the most intact forest fragments in that reserve, called Vila 5, which covers 180 ha at elevations between 160 and $288 \mathrm{~m}$ a.s.l. (Fig. 1) (Nascimento et al., 2017).
The specimens examined in this study were cleared with $10 \%$ potassium hydroxide $(\mathrm{KOH})$, neutralized with acetic acid $20 \%$, dehydrated in ethanol, diaphanized in clove oil and mounted in Canada balsam on slides. General morphological terminology follows Cumming \& Wood (2017). Cercus is preferred to the apical appendages of male terminalia following Araújo \& Bravo (2019). Additional information not included in the collection label was added in brackets in material examined. The type specimens and other material studied are deposited in the Entomological Collection Prof. Johann Becker of the Museu de Zoologia da Universidade Estadual de Feira de Santana, Bahia, Brazil (MZFS).

\section{TAXONOMY}

\section{Genus Tonnoira Enderlein, 1937}

Type species: Tonnoira pelliticornis Enderlein (orig. des.), known only by female.

Comments: Santos \& Curler (2014) provide an accurate diagnosis of Tonnoira. In some species of Tonnoira the $\mathrm{R}_{5}$ ends at pointed apex but other species this vein ends slightly beyond the apex, thus, these character states should be included in the diagnosis. 


\section{Tonnoira igrapiunensis sp. nov.}

Figs. 2-12

Type material: Holotype: male, BRAZIL, Bahia, Igrapiúna, Reserva Ecológica Michelin, Vila 5, 28.v-12. vii.2012, Malaise [trap]. Aragão, M.; Menezes, E.; Mota, E.; Andena, S, leg. (MZFS \#56225). Paratypes: 6 males, same data as holotype (MZFS \#56227, \#56229, \#56230, \#56231, \#56232, \#56233); 2 males, same locality as holotype, 27-28.x. 2012, light [trap], Aragão, M., Menezes, E., Mota, E. leg. (MZFS \#56226, \#56234); 1 male, same locality as holotype, 28.x-18.xi.2012, Malaise [trap], Aragão, M., Menezes, E. leg. (MZFS \#56228).

Description: Male: Head: slightly wider than long; short vertex; eye bridge with four facet rows; eyes separated by almost one facet diameter; interocular suture inverted Y-shaped (Fig. 2). Antenna: scape wider apically than at base, 2.0 times the length of the pedicel (Fig. 3); pedicel spherical, with two groups of three small sensorial setae both in front of and behind the proximal margin (Fig. 6); flagellum with 14 flagellomeres, all cylindrical (Figs. 3-5); ascoids not observed, probably lost; $14^{\text {th }}$ flagellomere with long apiculus, 0.3 times the length of the flagellomere (Fig. 5). Wing (Fig. 8): Sc short not reaching $C_{;} R_{2+3}$ not connected to $R_{4} ; R_{5}$ ending slightly beyond the wing apex; radial fork basal to medial fork. Terminalia: hypandrium bent backwards, narrower laterally (Fig. 9); gonocoxites 1.2 times the length of gonostyli, with setae only dorsally (Figs. 9, 11); gonostyli bifurcate; lateral branch of gonostylus longer than mesal branch (Figs. 9, 10), divergent in lateral view (Fig. 10); aedeagus bipartite, asymmetrical, short shaft 0.8 times the length of the long shaft; short shaft with two sclerites fused basally, dorsal sclerite platelike, shorter than the narrow ventral sclerite, both covered by an apical membrane (Fig. 9); parameres asymmetrical, long shaft with curved apex and short shaft plate-like with rounded apex (Figs. 9, 11); gonocoxal apodemes fused medially and articulated with parameres (Fig. 11); epandrium wider than long, bare ventrally, with one basal aperture (Fig. 12); hypoproct longer than epandrium, with apex tapered; epiproct shorter than hypoproct, with rounded apex; hypoproct and epiproct both with apical micropilosity (Fig. 12); cerci with two tenacula (Fig. 12).

Female: Unknown.

Remarks: The new species can be distinguished from other species of Tonnoira by the eye bridge with four facet rows, separated by 0.5 facet diameter; $R_{5}$ ending slightly posterior to apex of wing; gonostyli bifurcated, dorsal arm shorter than ventral arm; long arm of gonostyli shorter than length of gonocoxites; cerci with two tenacula; aedeagus bipartite, asymmetrical, short shaft 0.8 times the length of the long shaft; parameres asymmetrical, longer shaft with apex curved. The gonostylus is similar to that of T. andradei Santos, 2014, but differs, mainly, by the bifid aedeagus in the new species and with only one shaft in T. andradei. The ejaculatory apodeme and hypoproct in the new species is longer than the same structures in T. andradei.
Etymology: The species name is a reference to the municipality of Igrapiúna where the specimens of the new species were collected.

Distribution: Known only from the type locality.

\section{Tonnoira bifida Bravo \& Chagas, 2004}

Tonnoira bifida Bravo \& Chagas, 2004: 601, figs. 1-9.

Material examined: 1 male, BRAZIL, Bahia, Varzedo, Sr. Getúlio, x.2016, Dias \& Campos, leg. (MZFS).

Distribution: Brazil: Bahia, Serra da Jibóia (type locality: $12^{\circ} 52^{\prime} \mathrm{S}, 39^{\circ} 28^{\prime} \mathrm{W}, 720$ m.a.s.l.); Bahia, Varzedo (new record, $12^{\circ} 57^{\prime} 45.1^{\prime \prime}$ S, 39² $27^{\prime} 12.1^{\prime \prime}$ W, 280 m.a.s.l.).

\section{Tonnoira brisolaii Santos, 2014}

Tonnoira brisolaii Santos, 2014 (in Santos \& Curler, 2014): 464, figs. $1-5$.

Material examined: 1 male, BRAZIL, Bahia, Serra da Jibóia, Sede Gambá, 10.v.2017, Ligth [trap], Silva-Neto, Mendes \& Moura, leg. (MZFS).

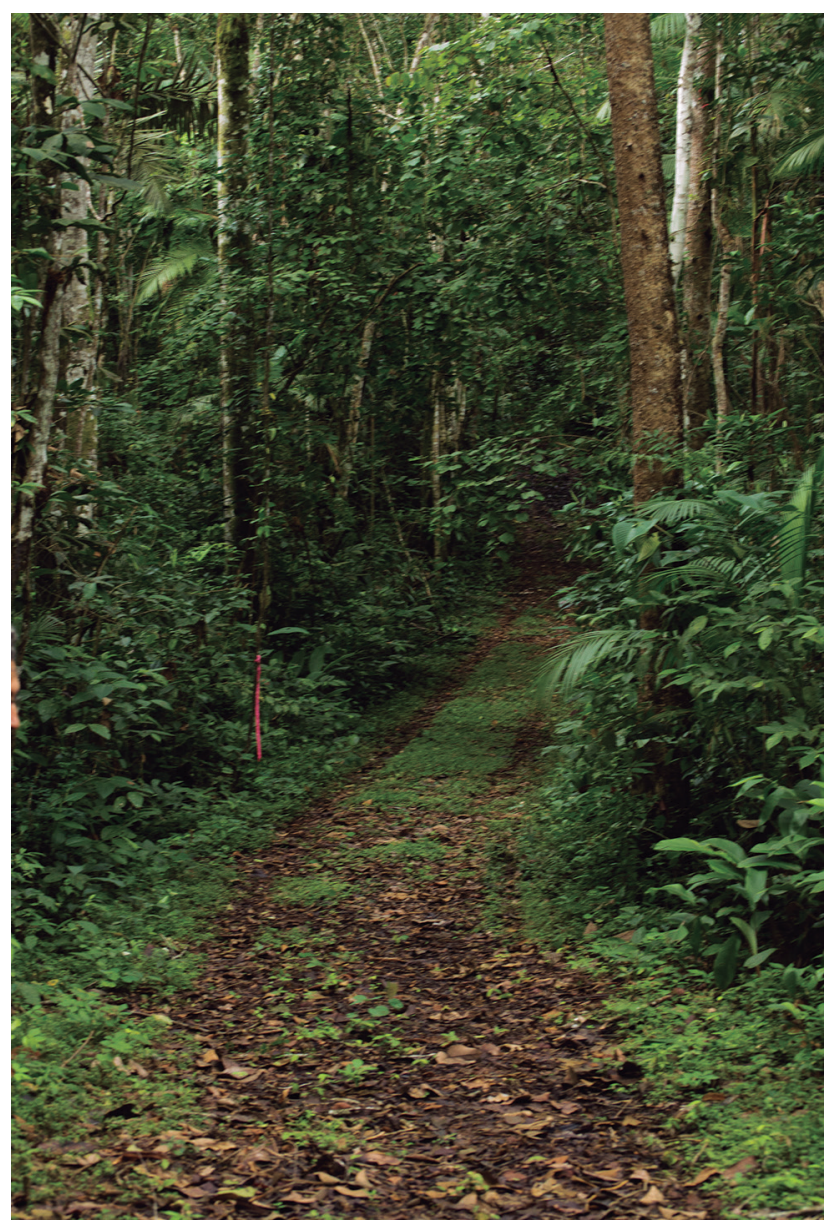

Figure 1. Atlantic Rain Forest in Reserva Ecológica Michellin, Vila 5. Photo by M. Aragão. 

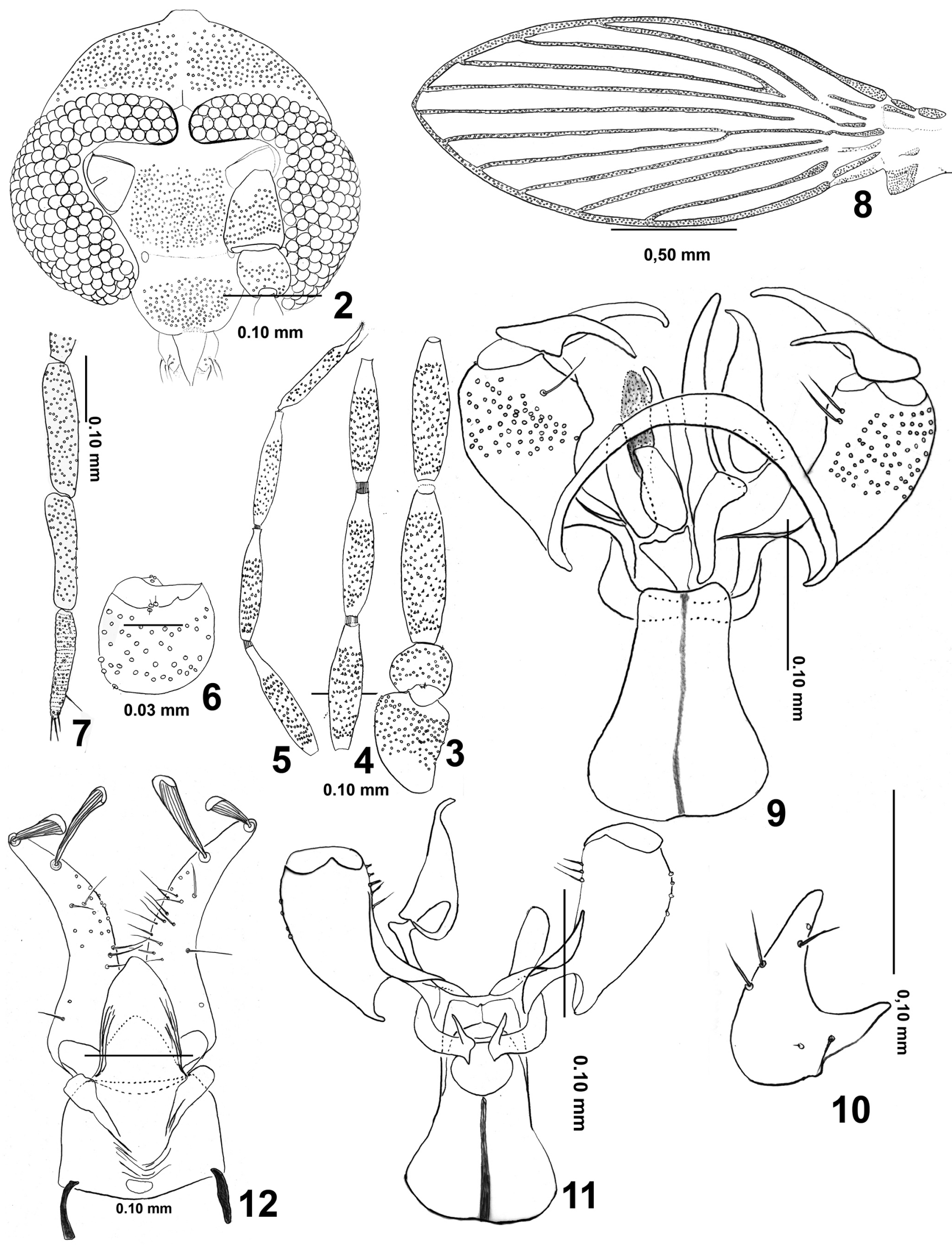

Figures 2-12. Tonnoira igrapiunensis sp. nov., adult male. (2) Head in frontal view (paratype 56227). (3) scape, pedicel and first flagellomeres (paratype 56227). (4) Flagellomeres 4, 5 and 6 (paratype 56227). (5) Apical flagellomeres and apiculus (paratype 56226). (6) pedicel with the marginal sensory setae (paratype 56227). (7) Palpus (paratype 56227). (8) wing. (9) Hypandrium, gonocoxites, gonostylus, ejaculatory apodeme, aedeagus and parameres (holotype). (10) gonostylus, lateral view (paratype 56227). (11) gonocoxites, gonocoxal apodemes fused, parameres and ejaculatory apodeme (holotype 56225). (12) Epandrium, cerci and hypoproct (paratype 56227). Abbreviations: am = apical membrane; Isae = long shaft of aedeagus; $\mathrm{pr}=$ paramere; ssae $=$ small shaft of aedeagus. 
Distribuição: Brazil: Espírito Santo, Santa Teresa, (type locality); Bahia, Serra da Jibóia (new record, $12^{\circ} 52^{\prime} \mathrm{S}$, $39^{\circ} 28^{\prime} \mathrm{W}, 720$ m.a.s.l.).

\section{Tonnoira galatiae Santos, 2014}

Tonnoira galatiae Santos, 2014 (in Santos \& Curler, 2014): 468, figs. 14-17.

Material examined: 3 males, BRAZIL, Bahia, Igrapiuna, Reserva Ecológica Michelin, Vila 5, 22.ix-28.x.2012, Malaise [trap]. Aragão, M.; Menezes, E. leg. (MZFS); 1 male same data as the previous one, except 16.xii.2012-20.i.2013 (MZFS); 2 males, same data as the previous one, except 20.i-24.ii.2013 (MZFS); 2 males, same data as the previous one, except 24.ii-31.iii.2013 (MZFS); 1 male, same data as the previous one, except 31.iii-28.iv.2013 (MZFS).

Distribution: Brazil: Espírito Santo, Santa Teresa (type locality: $19^{\circ} 54^{\prime} \mathrm{S}, 40^{\circ} 33^{\prime} \mathrm{W}, 820$ m.a.s.l.); Bahia, Igrapiúna (new record: $13^{\circ} 50^{\prime} \mathrm{S} ; 3^{\circ} 10^{\prime} \mathrm{W}, 160$ m.a.s.l.).

\section{Species included in Tonnoira}

Twenty-six species are recognized in Tonnoira: T. andradei Santos, 2014 (Brazil: Espírito Santo); T. bifida Bravo \&Chagas, 2004 (Brazil: Bahia); T. bifurcata Quate \& Brown,
2004 (Brazil: Rondônia); T. bitalea Quate, 1999 (Panama, Brazil: Amazonas); T. bitenacula Quate, 1996 (Costa Rica); T. brisolaii Santos, 2014 (Brazil: Espírito Santo); T. castanea Quate \& Brown, 2004 (Brazil: Amazonas, Suriname); T. cavernicola Quate \& Brown, 2004 (Bolivia, Guiana Francesa); T. didyma Quate \& Brown, 2004 (French Guiana, Suriname); T. distincta Bravo, Alves \& Chagas, 2008 (Brazil: Amazonas); T. ferreirai Santos, 2014 (Brazil: Espirito Santo); T. fusiformis Quate \& Brown, 2004 (Costa Rica, Ecuador); T. galatiae Santos, 2014 (Brazil: Espírito Santo); T. igrapiunensis sp. nov. (Brazil: Bahia); T. Iongipennis Bravo \& Chagas, 2004 (Brazil: Bahia); T. magna Bravo \& Chagas, 2004 (Brazil: Bahia); T. mirabilis Wagner, 1981 (Brazil: Amazonas, Suriname); T. pelliticornis (Peru); T. protuberata Quate \& Brown, 2004 (Venezuela); T. psacadoptera Quate \& Brown, 2004 (Venezuela); T. rapiformis Quate \& Brown, 2004 (Brazil, Suriname); T. rectilata Quate, 1999 (Nicaragua, Panama, Suriname, Brazil: Amazonas, Rondônia); T. robusta Bravo, Alves \& Chagas, 2008 (Brazil: Amazonas); T. sicilis Quate \& Brown, 2004 (French Guiana); T. spina Chagas-Vieira, 2012 (Brazil: Amazonas); T. tripenis Chagas-Vieira, 2012 (Brazil: Amazonas).

In Brazil, eighteen species of Tonnoira are recorded only from the Amazon and Atlantic Rain forests, two regions with high annual rainfall levels. Ten species occur in the Brazilian Amazon (states of Amazonas, Para, and Rondônia), and eight in the Atlantic Rain Forest (states of Espírito Santo and Bahia).

\section{Key to males of Tonnoira}

The male of the type species of the genus, T. pelliticornis, is unknown.

1. Gonostylus bifurcate

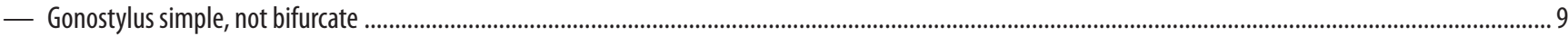

2. Gonostylus with lateral and mesal branches of different length; branches subparallel or divergent....................................................................................... 3

- Gonostylus with lateral and mesal branches of same length, crossed (Santos \& Curler, 2014: Fig. 4) T. brisolai

3. Lateral branch of gonostylus longer than mesal branch; mesal branch of gonostylus shorter than the length of gonocoxite (e.g., Santos \& Curler, 2014: fig. 12)...4

— Lateral branch of gonostylus shorter than mesal branch; mesal branch of gonostylus longer than the length of gonocoxite (e.g., Bravo \& Chagas, 2004: fig. 6)... 6 4. Eye bridge with 5 facet rows; cercus with one tenaculum .............................................................................................................................. protuberata

- Eye bridge with 4 facet rows; cercus with two tenacula.

5. Eyes separated by 0.5 facet diameter; parameres symmetrical (Santos \& Curler, 2014: fig. 12). T. andradei

— Eyes separated by almost 1 facet diameter; parameres asymmetrical (fig. 9) T. igrapiunensis sp. nov.

6. Lateral branch of gonostylus very short, 0.2 times the length of mesal branch (Santos \& Curler, 2014: fig. 8) .. T. ferrerai

— Lateral branch of gonostylus 0.4-0.6 times the length of mesal branch (e.g., Bravo \& Chagas, 2004: fig. 6)

T. bifurcata

7. Aedeagus with one branch apically U-shaped with one of the branchs longer than other (Quate \& Brown, 2004: fig. 69a) .. .7

- Aedeagus with two branches, none of them apically U-shaped. .. .8

8. Lateral branch of gonostylus with the same sclerotinization of mesal branch; hypandrium narrower than width of gonocoxite, strip-like (Quate \& Brown, 2004: fig. 70) T. didyma

— Lateral branch strongly sclerotinized; hypandrium wider than width of gonostylus (Bravo \& Chagas, 2004: fig. 6) ........................................................ T. bifida

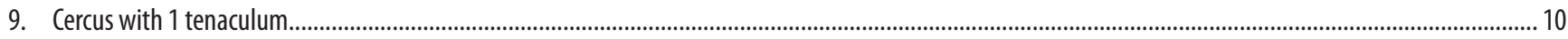

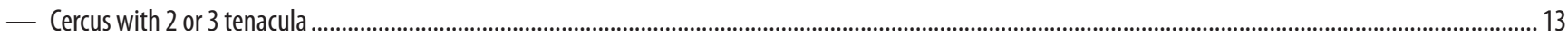

10. Base of $R_{3}$ with cluster of black "granules" (Quate \& Brown, 2004: fig. 63) ...................................................................................................... T. psacadoptera

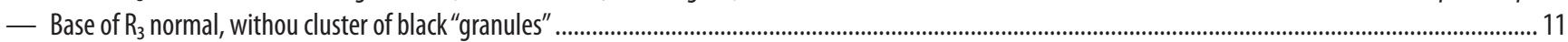

11. Hypandrium wide, of the same length of width of gonostylus; gonocoxite 0.8 times the length of gonostylus (Chagas-Vieira, 2012: fig. 16) .................T. tripenis

- Hypandrium stripe-like; gonocoxite about as long as gonostylus

12. Aedeagus "tripartite with short spur, a sickle shaped lateral shaft, and broad, paddle shaped central part twisted" (Quate \& Brown, 2004: p. 29, fig. 68) 
- Aedeagus "bipartite, larger shaft with basal three-quarters broad, asymmetrically narrowing at distal one-quarter, smaller shaft small, blunt, about one-half as long as other shaft" (Quate \& Brown, 2004: p. 27, fig. 67a) .......................................................................................................................... T. castanea

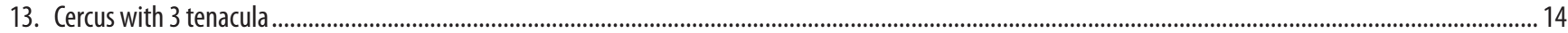

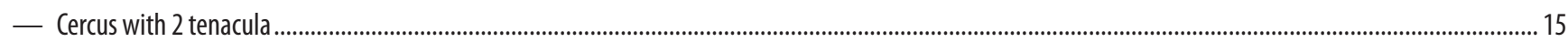

14. Aedeagus ending at the same level of apex of gonostylus; ejaculatory apodeme shorter than gonostylus (Wagner, 1981: fig. 3) .............................. T. mirabilis

— Aedeagus ending above of apex of gonostylus; ejaculatory apodeme longer than gonostylus (Chagas-Vieira, 2012: fig. 12).......................................... T. spina

15. Aedeagus symmetrical, base broad, apex sagittate; parameres absent (Quate, 1996: fig. 13b; Quate \& Brown, 2004: fig. 71) .............................................. 16

— Aedeagus symmetrical or asymmetrical, long, subcylindrical, pointed or rounded at apex; parameres present .................................................................. 17

16. Hypandrium present, strip-like; gonocoxite as wide as long (Quate, 1996: fig. 13b) ..................................................................................... T. bitenacula

— Hypandrium vestigial, broken in the middle; gonocoxite longer than wide (Quate \& Brown, 2004: fig. 71) ............................................................. T. rapiformis

17. Aedeagus ending far beyond the apex of gonostylus (Bravo \& Chagas, 2004: fig. 1).......................................................................................... T. longipennis

- Aedeagus ending near or just beyond the apex of gonocoxites, never beyond the apex of gonostylus ............................................................................. 18

18. Aedeagus sickle shaped; ejaculatory apodeme triangular, short (Quate \& Brown, 2004: fig. 77) ................................................................................ T. rectilata

— Aedegus straight or little curved; ejaculatory apodeme sub-oval, longer than wide ....................................................................................................... 19

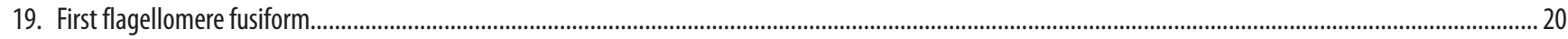

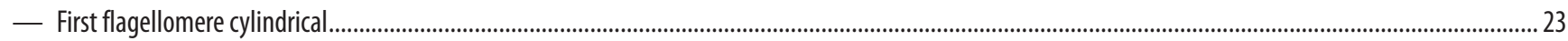

20. "Gonocoxal apodeme with pair of slender, acute processes flanking aedeagus and extending nearly to the tip of aedeagus" (Quate, 1999: p. 429, fig. 5K) ..........

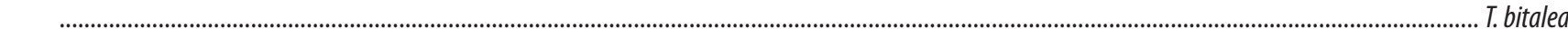

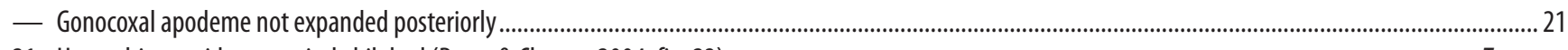

21. Hypandrium, wide, posteriorly bilobed (Bravo \& Chagas, 2004: fig. 23) ............................................................................................................ T. magna

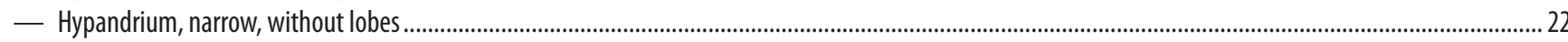

22. Eyes separated by 0.5 facet diameters; gonostylus shorter than gonocoxites; ejaculatory apodeme shorter than gonocoxite (Bravo et al., 2008: figs. 11, 16) .......

.. T. robusta

— Eyes separated by 0.2 facet diameters; gonostylus longer than gonocoxites; ejaculatory apodeme longer than gonocoxite (Santos \& Curler, 2014: fig. 16) ..........

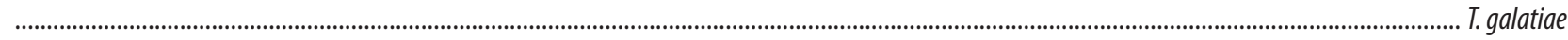

23. Aedeagus with one shaft, "abruptly narrowing to acute apex" (Quate \& Brown, 2004: p. 32, fig. 74) ................................................................... f. fusiformis

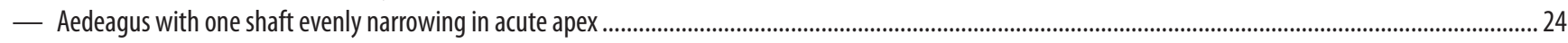

24. Eyes separated by less than 1 facet diameter; "aedeagus extending little beyond tip of gonocoxite” (Quate \& Brown, 2004: p. 31, fig. 72) ................ T. cavernicola

— Eyes separated by 1 facet diameter; aedeagus extending to half of gonostylus (Bravo et al., 2008: fig. 6) ................................................................ T. distincta

\section{ACKNOWLEDGEMENTS}

This study was financed in part by the Coordenação de Aperfeiçoamento de Pessoal de Nível Superior - Brasil (CAPES) - Finance Code 001. Freddy Bravo received a research grant from Conselho Nacional de Desenvolvimento Científico e Tecnológico (№ 306441/2015-2). Maíra Xavier Araújo also has a grant from CNPq (№ 150571/2018-6). We would like to thank the reviewers for their comments in the manuscript.

\section{REFERENCES}

Araújo, M.X. \& Bravo, F. 2019. Two new species of Lepidiella Enderlein, 1937 (Diptera: Psychodidae) from the Neotropical Region with taxonomic comments about the species of the genus. Zootaxa, 4551: 487-493.

Bravo F. \& Chagas, C. 2004. Espécies Novas de Tonnoira Enderlein (Diptera: Psychodidae) do Nordeste brasileiro. Neotropical Entomology, 33: 601-605.

Bravo, F.; Chagas, C. \& Alves, V.R. 2008. Description of two new species of Tonnoira Enderlein from caves in the Brazilian Amazon and comments about the taxonomic status of Tonnoira plumaria Quate (Diptera, Psychodidae, Psychodinae). Zootaxa, 1916: 63-68.
Chagas-Vieira, C. 2012. New records of Tonnoira Enderlein (Diptera, Psychodidae, Psychodinae) from the Brazilian Amazon with descriptions of two new species. Zootaxa, 3318: 51-56.

Cumming, J.M. \& Wood, D.M. 2017. 3. Adult morphology and terminology, pp. 51-63. In: Kirk-Spriggs, A.H. \& Sinclair, B.J. (Eds.). Manual of Afrotropical Diptera. Vol. 1. Introductory chapters and keys to Diptera families. Pretoria, South African National Biodiversity Institute. 1361p.

Nascimento, F.E.L.; Botero, J.P.; Aragão, M. \& Andena, S.R. 2017. Faunistic analysis of Cerambycidae (Insecta: Coleoptera) in an area of Atlantic Forest. Journal of Natural History, 51: 2429-2441.

Quate, L.W. 1996. Preliminary taxonomy of Costa Rican Psychodidae (Diptera), exclusive of Phlebotominae. Revista de Biología Tropical, 44(Suppl. 1): 1-81.

Quate, L. W. 1999. Taxonomy of neotropical Psychodidae (Diptera 3. Psychodines of Barro Colorado Island and San Blas, Panama. Memoirs on Entomology International, 14: 409-441.

Quate, L.W. \& Brown, B.V. 2004. Revision of Neotropical Setomimini (Diptera: Psychodidae: Psychodinae). Contribution in Science, Natural History Museum of Los Angeles, 500: 1-117.

Santos, C.B. \& Curler, G.R. 2014. Four new species of Tonnoira Enderlein (Diptera: Psychodidae, Psychodinae) from the Brazilian Atlantic forest. Zootaxa, 3760: 463-470.

Wagner, R. 1981. Two new moth-flies (Diptera, Psychodidae) from South America. Studies on Neotropical Fauna and Environment, 16: 217-220. 